\title{
MINERALIZACIÓN DE ORO EN LA FRANJA AURÍFERA DE VERAGUAS, PANAMÁ
}

\author{
Carl E. Nelson 1 \& Jorge Ganoza² \\ (1) Recursos del Caribe S.A., 2360 23rd. Street, Boulder, \\ Colorado 80304 USA, (303) 939-9517; \\ E-mail: cnelson945@aol.com \\ (2) El Oro Resources, 20 Calle 18-23, Zona 10, \\ Edificio Plaza Buro, Oficina 403, Guatemala, (502) 366-2912
}

(Recibido 4/11/1998; Aceptado 28/5/1999)

\begin{abstract}
Gold mineralization in the Veraguas Gold Belt of Panama is hosted by calc-alkaline volcanic rocks of mid-Miocene age. The volcanic rocks range in composition from basalt to rhyolite and are intruded by coeval exogenous plugs and domes. Pyroclastic aprons surround the domes and host the ore deposits. The Remance mine, a vein and vein stockwork, has produced gold intermittently for over a century. Santa Rosa, a shallow epithermal stockwork and disseminated deposit, went into production in 1995. Gold discoveries in the Veraguas Belt focus attention on the exploration potential of hot spring systems and dome fields throughout Central America.
\end{abstract}

RESUMEN: La mineralización de oro en la Franja Aurífera de Veraguas, Panamá, está contenida en rocas de edad Miocénica media, de composición calco-alcalina. Estas rocas tienen un rango de composición que va desde basalto hasta riolita y están intruidas por cuellos volcánicos y domos exógenos coevales.

Cubiertas piroclásticas rodean los domos y contienen depósitos minerales. La mina Remance, un sistema de vetas y stockworks, ha producido oro intermitentemente por más de cien años. Santa Rosa, un sistema epitermal somero de oro diseminado y en stockworks, entró en producción en 1995. Descubrimientos de oro en la Franja Veraguiense centran la atención en el potencial para la exploración que tienen los sistemas tipo fuente termal y en los campos de domos a lo largo de Centro América.

\section{INTRODUCCIÓN}

Depósitos de oro diseminado y en stockwork contenidos en campos de domos representan importantes objetivos para la exploración en la cuenca caribeña y el arco circum-pacífico. En América Central, el primero de estos depósitos en entrar en producción fue la mina Remance
(Panamá), en 1989. Desde entonces, nuevos descubrimientos en los campos de domos han sido anunciados en Santa Rosa, Panamá (1,0 millón de onzas), Crucitas en Costa Rica (2,2 millones de onzas) y San Andrés en Honduras (0,85 millones de onzas). Los tamaños de los depósitos que se mencionan en este trabajo están referidos a sus recursos auríferos publicados al mes de octubre de 1997. Aún cuando depósitos de talla mundial (más de 5 
millones de onzas) todavía no han sido descubiertos en Centro América, depósitos como Yanacocha en Perú (11,3 millones de onzas), dan evidencia del potencial de este ambiente geológico, visto desde la perspectiva del arco circum-pacífico.

Este trabajo describe campos de domos, mantos piroclásticos, y la mineralización de oro relacionada en la Franja Aurífera de Veraguas, Panamá. Dos depósitos, Santa Rosa y Remance se encuentran en producción actualmente. Un mapa de ubicación y otro geológico se presentan en las figuras 1 y 2 respectivamente.

\section{MINERALIZACIÓN AURÍFERA EN CAMPOS DE DOMOS CENTROAMERICANOS}

Domos exógenos cuyo composición varía desde basaltos a riolitas intruyen rocas volcánicas del arco de isla a lo largo de Centroamérica.
Mantos piroclásticos rodean varios de estos complejos de domos y algunos de estos campos de domos se encuentran afectados por alteración hidrotermal. Los depósitos de oro asociados se encuentran dentro de los mantos piroclásticos que se formaron alrededor de cuerpos intrusivos someros o „plugs“ (p.ej. Santa Rosa) y en los mismos domos (p.ej. Crucitas).

Los campos de domos centroamericanos se encuentran típicamente a lo largo de una disconformidad que separa andesitas propilitizadas regionalmente de rocas sobreyacientes de la misma composición pero solo levemente alteradas. La alteración propilítica regional está caracterizada por la paragénesis cuarzo - clorita - calcita, producto de la circulación de aguas marinas y meteóricas en un arco de isla emergente. Estructuras en almohadilla se observan en la Formación Cañazas, en el occidente panameño (drenaje del río Vigui), lo cual indica que esa porción de las andesitas propilitizadas regionalmente fue emplazada bajo agua.

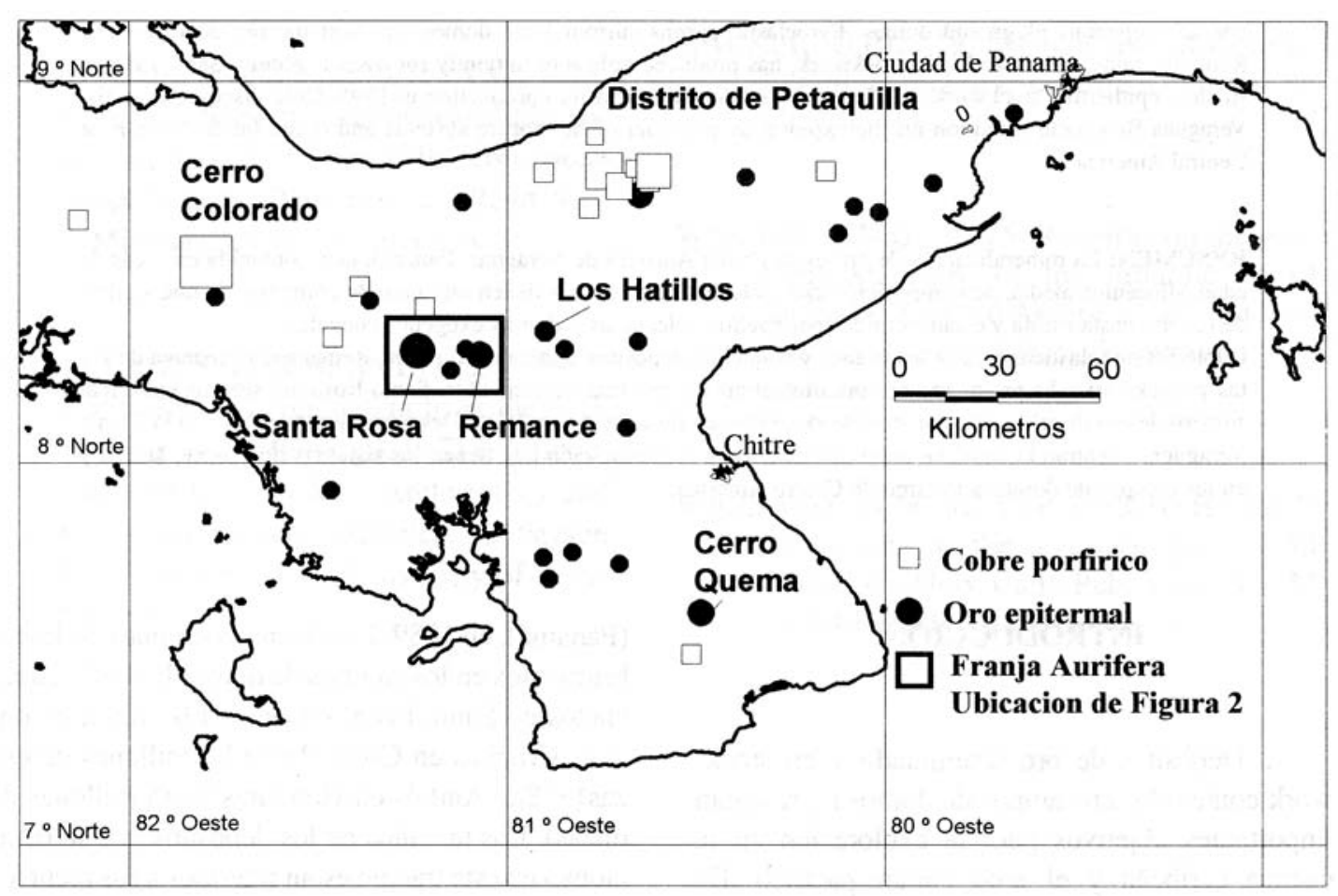

Fig. 1: Mapa de ubicación de oro y cobre en Panamá Central y la Franja Aurífera de Veraguas. 


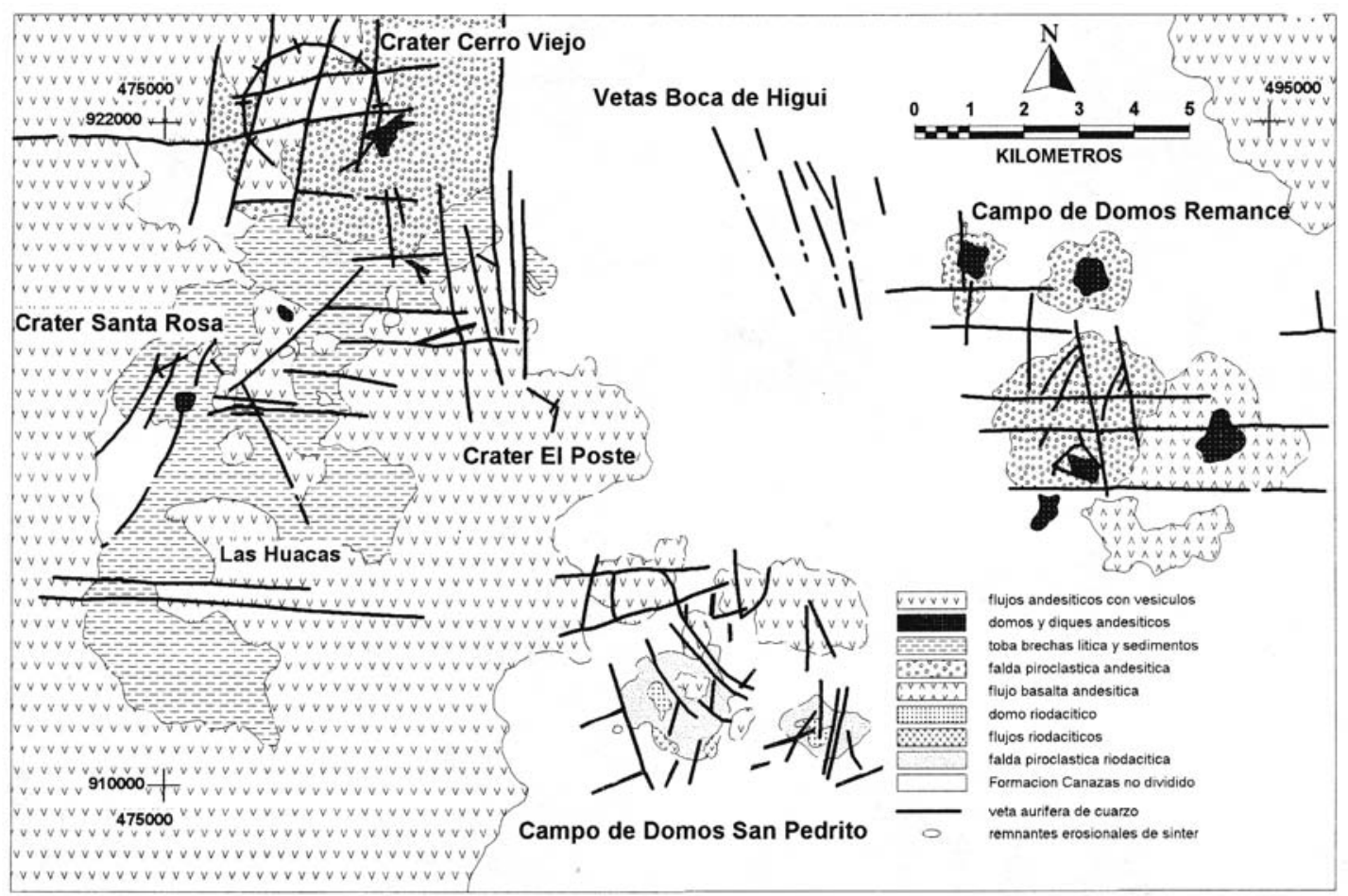

Fig: 2: Mapa geológico de la Franja Aurífera de Veraguas.

Un ambiente volcánico subacuático somero provee las condiciones ideales para la mezcla de agua y magma, desatando así consecuentes erupciones freatomagmáticas.

Este ambiente volcánico es similar al del lago de Nicaragua, donde en la actualidad un campo volcánico esta emergiendo del lago, el cual alguna vez estuvo abierto al océano. Las erupciones hidrovolcánicas son comunes mientras estos edificios volcánicos del arco de isla hacen su transición del volcanismo subacuático al subaéreo.

En este trabajo los términos freatomagmático, hidrovolcánico y erupción maárica son términos intercambiables; todos se refieren a erupciones en las cuales la energía explosiva se deriva de la mezcla de agua y magma. Este tipo de actividad eruptiva ocupa un terreno medio entre erupciones volcánicas a un extremo del espectro y erupciones hidrotermales al otro. Las erupciones volcánicas se derivan enteramente de la energía contenida en el magma. Los depósitos piroclásticos asociados a estos eventos contienen únicamente material magmático juvenil como fragmentos de vidrio volcánico y pómez. Las erupciones hidrotermales (incluyendo geysers) son mucho menos poderosas y son desatadas por la energía contenida en la roca y el reservorio de agua (Nelson \& Giles, 1985). El producto de su explosión no contiene material magmático juvenil. En el campo, la ocurrencia en combinación de fragmentos líticos y material magmático juvenil son usados para inferir una mezcla de agua y magma durante la erupción.

Los productos de erupciones hidrovolcánicas son brechas líticas lapilíticas sin uniformidad en su granulometría, las cuales típicamente gradan desde una roca con soporte de clastos y compuesta por fragmentos gruesos en la base a una roca con soporte de matriz de grano fino en la parte alta. Los clastos son subangulares a subredondeados e incluyen fragmentos líticos, fragmentos de pómez y fragmentos de brecha 

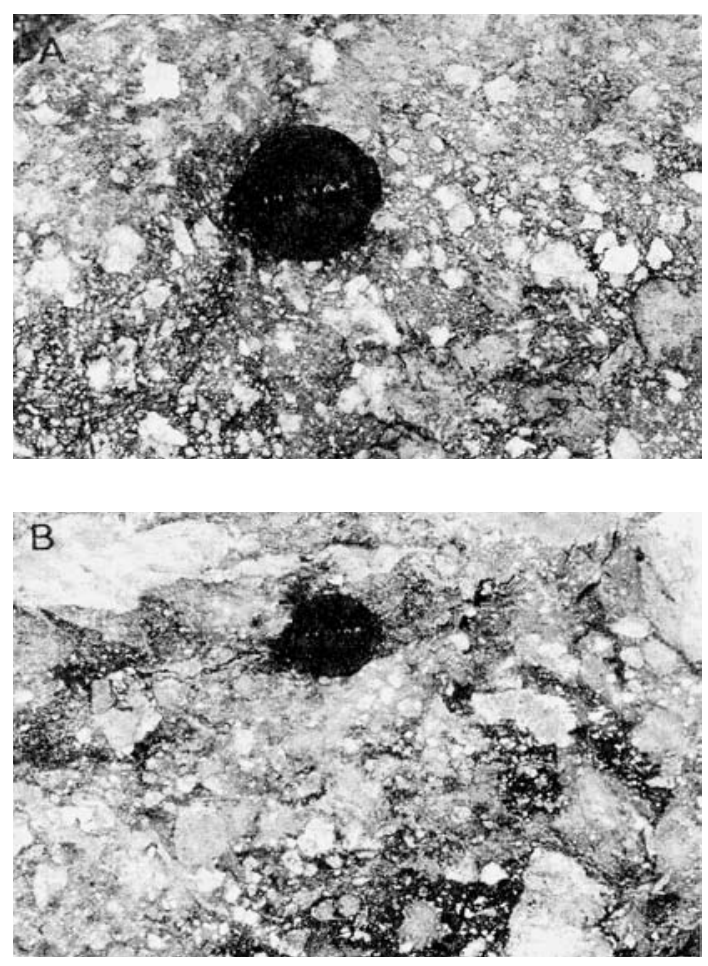

Fig. 3: Brecha de la serie piroclástica, Santa Rosa. A. Brecha con matriz y fragmentos con alteración argílica. La matriz es un lodo piroclástico. B. Brecha con lentes sedimentarias.

lítica lapilítica. La matriz es una mezcla de ceniza volcánica y polvo de roca. Ejemplos de una brecha lítica lapilítica del depósito Santa Rosa se aprecian en la figura 3.

Las brechas líticas lapilíticas pueden llegar a cubrir varias decenas de kilómetros cuadrados y proveen una herramienta para localizar campos de domos exógenos. Brechas con alteración hidrotermal que exhiben evidencia de actividad hidrovolcánica e hidrotermal contemporánea son especialmente indicativas para una mineralización epitermal de oro. La presencia de clastos silicificados indica que el sistema hidrotermal se encontraba activo durante las erupciones hidrovolcánicas. Un gran número de sistemas de fuente termal con oro (p.ej. McLaughlin, California) exhiben evidencia de alteración hidrotermal y actividad volcánica explosiva coincidentes en espacio y tiempo. Los conductos de la erupción hidrovolcánica proveen canales para la circulación de fluidos hidrotermales,
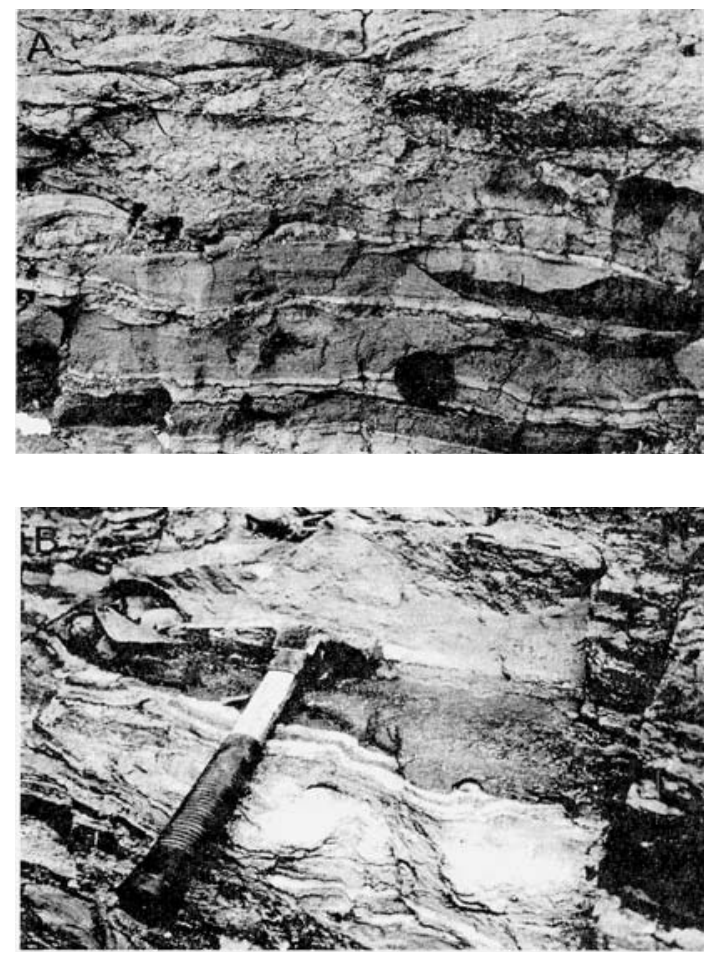

Fig. 4: Unidades de origen piroclástica y epiclástica. A. Brecha con estratos de sedimento carbonáceo, Santa Rosa. B. Brecha intercalada con sedimentos epiclásticos carbonáceos, Pueblo Viejo, Republica Dominicana.

que a su vez, concentran la mineralización de metales preciosos. Brechas líticas lapilíticas que contengan clastos silicificados pueden ser usadas como guía en la búsqueda de sistemas tipo fuente termal en rocas volcánicas del arco de isla.

En la Franja Aurífera de Veraguas, mantos piroclásticos se entrelazan con una secuencia de sedimentos carbonosos, finamente estratificados y brechas líticas lapilíticas epiclásticas. Esta secuencia contiene el grueso de las reservas de oro en la mina Santa Rosa y es muy similar al miembro Pueblo Viejo de la Formación Los Ranchos en la República Dominicana (Fig. 4). Un ambiente marino somero o lagunar se infiere para los depósitos Santa Rosa y Pueblo Viejo, basado en la presencia de fósiles de plantas terrestres en los sedimentos. Sedimentos epiclásticos finamente estratificados también proveen una herramienta para la exploración de oro en secuencias volcánicas de arco de isla. 


\section{GEOLOGÍA DE LA FRANJA AURÍFERA DE VERAGUAS}

Las rocas volcánicas de la Franja Aurífera de Veraguas varían en composición desde basalto (fenocristales de plagioclasa y piroxeno) a riolita (fenocristales de cuarzo, biotita y hornblenda). Análisis por fluorescencia de rayos-X de 19 muestras sin alteración arrojan una variación desde menos de 50 a más de $70 \%$ de $\mathrm{SiO}_{2}$. Los domos tienen una composición igual a los flujos y rocas piroclásticas asociadas (Fig. 5). Un gráfico de potasio versus silica (Fig. 6) muestra una distribución de composición que va desde calco-alcalino normal a calco-alcalino rico en potasio. Esta tendencia hacia un contenido alto en potasio se refleja en la presencia substancial de alteración a feldespato potásica en Santa Rosa. El feldespato potásico secundario (adularia) es un producto de alteración común en el depósito de Crucitas en Costa Rica. Aún cuando la alteración potásica no es rara en los depósitos epitermales, cuando ocurre como un remplazamiento de grano fino, se confunde fácilmente con rocas félsicas (p.ej. latita, riolita).

Todas las unidades de rocas volcánicas en la Franja Aurífera de Veraguas están asignadas a la Formación Cañazas, de edad Miocénica. Dataciones radiométricas $\mathrm{K}-\mathrm{Ar}$ en flujos basálticos vitricos del tajo abierto de Alto de la Mina en Santa Rosa dieron edades de 16,6 +/- 0,6 Ma. Esta edad es semejante a la reportada por Wleklinski (1969) de 17,5 +/- 0,6 Ma, para flujos basalto andesíticos del distrito de los Hatillos a unos

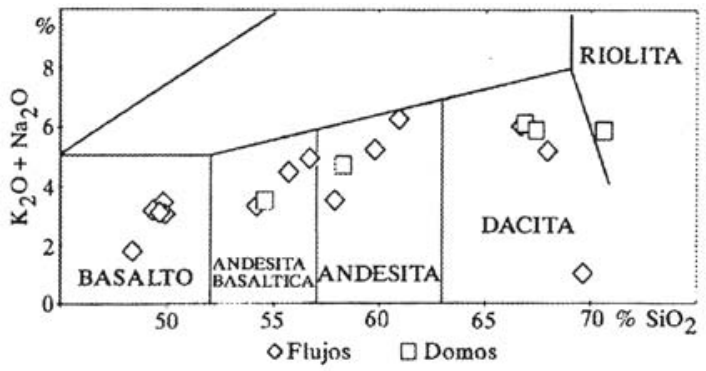

Fig. 5: Potasio $\left(\mathrm{K}_{2} \mathrm{O}\right)+$ sodio $\left(\mathrm{Na}_{2} \mathrm{O}\right)$ versus sílice $\left(\mathrm{SiO}_{2}\right)$ de 19 muestras de rocas volcánicas de la Franja Aurífera de Veraguas.

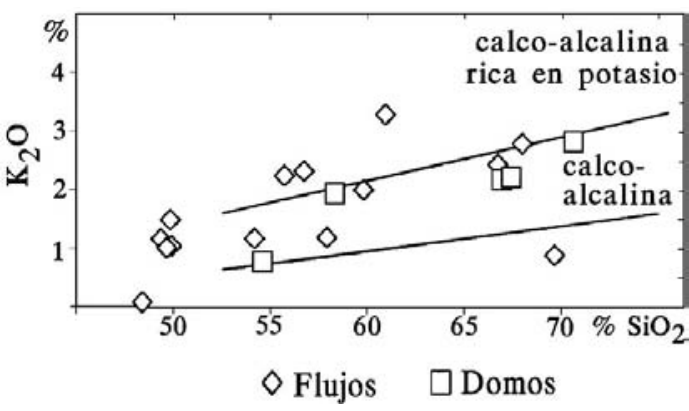

Fig. 6: Potasio (K2O) versus sílice (SiO2) de 19 muestras de rocas volcánicas de la Franja Aurífera de Veraguas.

veinte kilómetros al este de la mina Santa Rosa. Ignimbritas de la Formación La Yeguada, las cuales sobreyacen las rocas volcánicas de la Formación Cañazas, han dado edades de 12,6 +/- 0,8 Ma (Wleklinski, 1969).

El Cerro Viejo, el centro volcánico más grande en la Franja Aurífera de Veraguas, está localizado a unos kilómetros al norte del depósito de oro Santa Rosa y se encuentra alterado hidrotermalmente en su flanco este (Fig. 7). Tobas líticas lapilíticas con alteración propilítica forman la base del volcán y están sobreyacidas por flujos basálticos sin alterar que buzan hacia la parte externa del cráter. Otros cráteres, cada uno flanqueado por flujos, han sido confirmados mediante mapeo geológico en El Poste y Remance y a unos kilómetros más hacia el este en La Honda y Los Hatillos-Aguacatal. Los cráteres mejor preservados son Cerro Viejo y El Tullido en la mina Remance (Fig. 7). Mapeos geológicos a detalle alrededor del cráter del Tullido demuestran que las unidades piroclásticas son más gruesas y el tamaño de los fragmentos aumenta hacia el cráter (en realidad dos cráteres superpuestos). Un domo andesítico exógeno ocupa el cráter del Tullido y cubre parcialmente su propia capa piroclástica.

Evidencia de actividad intrusiva es común en la Franja Aurífera de Veraguas. Cuellos volcánicos, diques y domos exógenos con bandeamiento de flujo afloran a lo largo de una franja que mide aproximadamente $40 \mathrm{~km}$ de largo (esteoeste) y $20 \mathrm{~km}$ de ancho (norte-sur). Existen dos domos o "plugs" cerca de la mina Santa Rosa, 

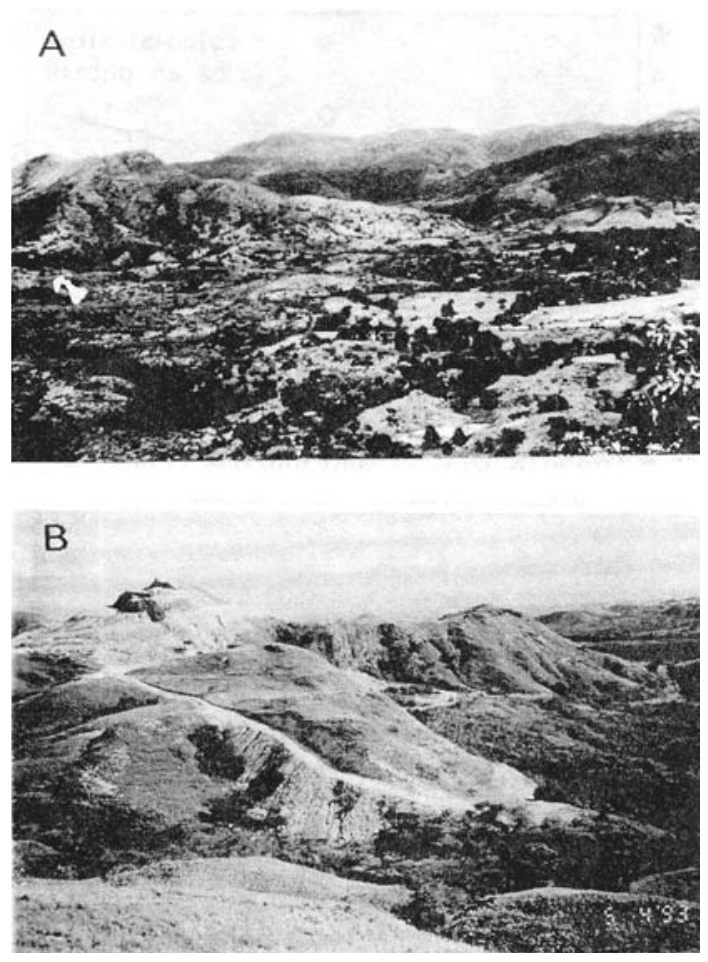

Fig. 7: Morfología volcánica en la Franja Aurífera de Veraguas. A. Cráter del Cerro Viejo visto desde Santa Rosa. B. Crater Tullido, Remance. dos en San Pedrito, uno en Cerro Viejo y tres en la mina Remance. Los diques son aún más numerosos y en Alto de la Mina, el primer depósito de oro en ser minado en Santa Rosa, la actividad ígnea somera esta claramente relacionada con la mineralización. Un dique basáltico y una brecha de conducto hidrotermal se encuentran emplazados en la misma falla con rumbo noroeste. La intrusión del dique probablemente desató la erupción hidrotermal que ahora forma un importante receptor de mineralización. Este ambiente geológico es similar al del campo geotermal activo de Waimangu en Nueva Zelanda donde, en 1904, intrusiones de diques a lo largo de una falla desataron erupciones a lo largo de la misma estructura.

Stockworks de gran tonelaje y depósitos de oro diseminado en la Franja Aurífera de Veraguas se formaron en un campo de domos y cráteres hidrovolcánicos. Tobas líticas lapilíticas entrelazadas con sedimentos carbonosos finamente estratificados ocupan aproximadamente $12 \mathrm{~km}^{2}$ en Santa Rosa y cuatro km² en Remance. El bajo nivel erosional del área esta indicado por formas volcánicas bien preservadas. Remanentes de depósitos de sinter silíceo indican que la

Tabla 1

Minas y prospectos de la Franja Aurifera de Veraguas

\begin{tabular}{lll}
\hline Deposito & Produccion Pasada/Reserva & Referencias \\
\hline Remance & $162 \mathrm{~kg}(5231$ onzas) de 15.500 toneladas de mena (siglo 19) & Wleklinski (1969) \\
& $\begin{array}{l}\text { Reserva de } 250.000 \text { toneladas con 5,5 ppm Au establecida por } \\
\text { Minera Remance cuando la Mina abrio en 1989. }\end{array}$ & \\
& & \\
Santa Rosa & Reserva minable de $12,4 \mathrm{M}$ t con $1,49 \mathrm{ppm} \mathrm{Au.}$ & White (1993) \\
& Reservas posibles implica un total de 22,7 M t con 1,4 ppm Au & Johnson et al. (1995) \\
& cero produccion pasada. & Johnson et al. (1996) \\
Los Hatillos & 30.000 toneladas con 12,5 ppm Au y 21,6 ppm Ag en reservas estimadas. & Wleklinski (1969) \\
& producción pasada desconocido, 6 tuneles & \\
Las Huacas & Construido por el Panama Corporation. & \\
San Pedrito & producción pasada menor de túneles y trincheras. & \\
Aguacatal & producción pasada menor de túneles y trincheras. & \\
\hline
\end{tabular}


mineralizacion de oro era poco profunda y relacionada con fuentes termales.

Las vetas en la Franja Aurífera de Veragua tienen un rumbo norte a noroeste con buzamientos bastante inclinados. También están presentes fallas y diques con rumbo noreste pero normalmente no se encuentran mineralizados. Las fallas mineralizadas probablemente se abrieron como respuesta a movimientos longitudinales de las estructuras regionales con rumbos oeste y noroeste. Vetas con rumbo norte y noroeste se encuentran a lo largo de toda la franja Aurífera de Veraguas, una distancia de más de $40 \mathrm{~km}$. Las vetas llegan a tener un espesor de hasta dos metros y están rellenas por cuarzo calcedónico bandeado y crustiforme y un poco de pirita. La mayoría de las vetas contiene valores erráticos de oro y muchos de los drenajes del área revelan oro visible en concentrados de batea.

Esfuerzos de exploración en la Franja Aurífera de Veraguas han llevado al descubrimiento de dos depósitos económicos de oro, Santa Rosa y Remance. La tabla 1 presenta una lista de minas y prospectos junto con información de producción histórica y recursos anunciados al mes de octubre de 1997.

\section{DEPÓSITO SANTA ROSA}

\section{Historia de Exploración}

La mineralización de oro en Santa Rosa fue descubierta durante los primeros años de este siglo y fue trabajada a pequeña escala por la empresa Panamá Corporation hasta antes de la gran depresión de los años 1930. Un pique fue excavado en Alto de la Mina y túneles en Santa Rosa y las Huacas. Durante los años setenta, la Dirección General de Recursos Minerales (DGRM) perforó dos pozos en Alto de la Mina.

La empresa Freeport de Panamá, S.A. adquirió la concesión de Santa Rosa y perforó aproximadamente $25.000 \mathrm{~m}$ entre los años 1986 y 1989, antes de vender todas sus propiedades en Panamá en el año 1990. El recurso geológico estimado al momento de la venta era de 12,4 millones de toneladas con 1,98 ppm de oro (793.000 onzas troy). La empresa Greenstone Resources perforó adicionalmente $32.700 \mathrm{~m}$ en los años 1990 y 1991 y completó un estudio de pre-factibilidad en el año 1991 el cual reportó reservas minables de 7 millones de toneladas con 1,58 ppm de oro (357.000 onzas troy). Para el mes de Junio de 1994 la reserva minable había sido incrementada a 12,3 millones de toneladas con 1,486 ppm de oro (591.800 onzas troy) y el recurso geológico se encontraba en 22,7 millones de toneladas con 1,4 ppm de oro (1,02 millones de onzas). El minado en Santa Rosa empezó en 1994 y la primera producción de oro en el mes de Junio de 1995.

\section{Geología}

La mineralizacion aurífera en Santa Rosa se formó en un ambiente tipo fuente termal en el margen de un cráter de erupción hidrovolcánica (maar). El cráter de Santa Rosa, ahora erosionado, mide aproximadamente dos kilómetros de diámetro. Porciones de la capa piroclástica, cerca de la pared del cráter, exhiben fragmentos gruesos, estratificación gradacional inversa y estratificación cruzada, lo cual sugiere una oleada piroclástica como mecanismo de emplazamiento. Dentro del cráter, unidades sedimentarias y epiclásticas intercaladas se angostan hacia las paredes del cráter. La mineralización se concentra dentro de brechas líticas lapilíticas, sedimentos epiclásticos carbonosos y flujos basálticos sobrepuestos.

Las rocas intrusivas en el área de la mina incluyen un domo dacítico con bandeamiento de flujo (Cerro Pelón), un „plug“ basáltico porfídico (Cerro Plata) y un dique basáltico (Alto de la Mina). El porfido basáltico inalterado en Cerro Plata contiene fenocristales de augita, hipersteno y plagioclasa. Las intrusiones basálticas provocaron erupciones hidrovolcánicas locales. Los cráteres y conductos resultantes de estas erupciones localizaron el movimiento de los fluidos hidrotermales convirtiendose así en centros de mineralización de oro. La mineralizacin descubierta a la fecha se ubica a lo largo del margen norte del cráter de 
Santa Rosa (Fig. 2) y alrededor de un conducto de brecha hidrotermal en Alto de la Mina.

La brecha hidrotermal del conducto en Alto de la Mina tiene aproximadamente $10 \mathrm{~m}$ de ancho por $60 \mathrm{~m}$ de largo. La brecha está compuesta por fragmentos poco homogéneos, gruesos, heterolíticos y ocasionalmente contiene fragmentos silicificados en una matriz barrosa de polvo de roca. La alteración de la roca no permite la identificación de fragmentos de pómez y vidrio volcánico que permitieron una distinción entre un origen hidrotermal o hidrovolcánico de la brecha. El borde del conducto es un contacto empinado e irregular con flujos basálticos en los alrededores. La mineralización está distribuida en forma de embudo, centrada en la brecha de conducto.

\section{Alteración y Mineralización}

En Santa Rosa la alteración feldespática esta confinada a fallas mineralizadas y conductos hidrotermales. En su mayoría, la mineralización está acompañada por un padrón de alteración cuarzo-siderita-pirita, el cual es gradacional hacia la parte externa del yacimiento pasando de una zona de alteración argílica a otra de alteración propilítica regional débil, la cual consiste de carbonato - clorita - cuarzo.

En la tabla 2 se presentan datos geoquímicos representativos de distintas rocas y tipos de alteración hidrotermal, variando desde la roca caja sin alterar hasta vetas y brechas de alta ley. En la tabla 3 se presentan datos similares para el yacimiento de Remance. La roca caja para ambos yacimientos incluye flujos basalto-andesíticos y brechas. Los análisis realizados incluyen 31 elementos pero solo los elementos base, metales preciosos y elementos guía se presentan en este trabajo. Los valores para el oro y la plata son elevados, así como para los elementos guía, arsénico, antimonio y mercurio. Los valores para los metales base son bajos a excepción de valores altos localizados en vetas y brechas hidrotermales. La variación en los elementos Mo, W, Li, Cd, Co, Ni, Cr, Bi, Be y Te es mínima.

\section{LAS HUACAS - LOS SÁNCHEZ}

El área de Las Huacas - Los Sánchez está localizada tres kilómetros al sur de la mina Santa Rosa (Fig. 2). En esta área la empresa Panama Corporation excavó seis galerías unos años antes de la gran depresión de los años 1930. La empresa Minas Santa Rosa, S.A. reabrió estas galerías en el año 1990. En las galerías se encontró localmente una mineralización de oro dentro de una sección alterada mixta, compuesta de rocas piroclásticas y epiclásticas, cerca del contacto con flujos basalto-andesíticos superiores (Fig. 2). Ocho perforaciones fueron realizadas en los años 1991 y 1994.

La secuencia mixta de rocas piroclásticas y epiclásticas continua al sur hasta Los Sánchez. Aunque la exploración de esta área todavía está en una fase temprana, concentrados de batea de sedimentos de los ríos del área contienen oro visible de forma consistente. En general, se encuentra oro donde los riachuelos drenan la sección mixta de rocas piroclásticas y epiclásticas.

\section{BOCA DE HIGUI}

Boca de Higui es un enjambre de vetas de cuarzo con rumbo norte - sur dentro de flujos andesíticos con alteración propilítica y brechas líticas (Fig. 2). Aunque el área no ha sido cartografiado en detalle, las perforaciones realizadas por Minas Santa Rosa, S.A. en 1994 confirmaron la presencia de flujos andesíticos y una secuencia inferior de sedimentos epiclásticos carbonosos finamente estratificados e intercalados con brechas líticas lapilíticas.

Pequeñas excavaciones en la superficie y morteros de piedra son evidencia de una limitada producción en el pasado, en su mayoría de la mina Vasco, cercana al nacimiento del río Higui. Siete perforaciones realizadas por Minas Santa Rosa, S.A. cerca de la mina Vasco cortaron secciones irregulares de mineralización. Todavía puede existir potencial sin explorar en la secuencia piroclástica alterada. 
Tabla 2

Datos geoquímicos de la Mina Santa Rosa (valores de Ag, As, $\mathrm{Sb}, \mathrm{Cu}, \mathrm{Pb}$ y $\mathrm{Zn}$ en ppm; $\mathrm{Au}$, y $\mathrm{Hg}$ en ppb)

\begin{tabular}{|c|c|c|c|c|c|c|c|c|c|}
\hline Muestra & Descripción & $\mathrm{Au}(\mathrm{ppb})$ & $\mathrm{Ag}$ & As & $\mathrm{Hg}(\mathrm{ppb})$ & $\mathrm{Sb}$ & $\mathrm{Cu}$ & $\mathrm{Pb}$ & $\mathrm{Zn}$ \\
\hline pasr-22 & argílica & 635 & 4,1 & 48 & 80 & 0,6 & 64 & 22 & 86 \\
\hline pasr-42 & argílica & 730 & 2,2 & 63 & 160 & 1,2 & 54 & 2 & 62 \\
\hline pasr-5 & argílica & 60 & 0,6 & 60 & 50 & 4,8 & 15 & 6 & 16 \\
\hline pasr-14 & argílica & 75 & 2,6 & 1000 & 50 & 33 & 8 & 10 & 6 \\
\hline pasr-18 & argílica & 175 & 1,2 & 50 & 410 & 2,8 & 11 & 20 & 192 \\
\hline pasr-8 & argílica & 20 & 0,3 & 60 & 100 & 0,6 & 56 & 12 & 22 \\
\hline pasr-32 & feldspática & 480 & 6,5 & 100 & 110 & 1,4 & 19 & 18 & 32 \\
\hline pasr-31 & feldspática & 16457 & 4,3 & 80 & 60 & 1,4 & 24 & 18 & 24 \\
\hline pasr-15 & brecha hidrotermal & 110 & 2,4 & 1600 & 20 & 19,4 & 13 & 10 & 12 \\
\hline pasr-4 & brecha hidrotermal & 1080 & 30 & 2500 & 360 & 46 & 22 & 6 & 12 \\
\hline pasr-25 & propilítica & 420 & 435,4 & 12 & 70 & 18 & 106 & 164 & 542 \\
\hline pasr-26 & propilítica & 15 & 20 & 6 & 10 & 1,8 & 50 & 20 & 118 \\
\hline pasr-33 & propilítica & 35 & 1,6 & 23 & 80 & 4 & 82 & 12 & 72 \\
\hline pasr-37 & propilítica & 2,5 & 0,2 & 50 & 40 & 2,8 & 55 & 6 & 78 \\
\hline pasr-36 & propilítica & 2,5 & 0,2 & 35 & 90 & 1 & 53 & 12 & 84 \\
\hline pasr-35 & silícea & 7040 & 7,1 & 90 & 170 & 1,2 & 80 & 8 & 72 \\
\hline pasr-17 & silícea & 580 & 3,8 & 53 & 20 & 1,2 & 48 & 18 & 44 \\
\hline pasr-13 & silícea & 2,5 & 0,1 & 400 & 200 & 22 & 21 & 6 & 60 \\
\hline pasr-2 & silícea & 48412 & 50 & 80 & 10 & 36 & 28 & 8 & 16 \\
\hline pasr-16 & silícea & 745 & 55 & 2400 & 460 & 35 & 30 & 8 & 16 \\
\hline pasr-1 & silícea & 80 & 50 & 530 & 150 & 16,4 & 75 & 10 & 6 \\
\hline pasr-19 & silícea & 30 & 1,3 & 9 & 60 & 0,7 & 36 & 1 & 62 \\
\hline pasr-20 & silícea & 20 & 0,1 & 6 & 60 & 0,6 & 39 & 4 & 58 \\
\hline pasr-39 & silícea & 4340 & 20 & 43 & 90 & 0,4 & 32 & 4 & 46 \\
\hline pasr-7 & silícea & 115 & 3,8 & 6200 & 190 & 74 & 17 & 6 & 14 \\
\hline pasr-6 & silícea & 210 & 13,5 & 10000 & 780 & 110 & 26 & 12 & 8 \\
\hline pasr-10 & sinter & 5 & 0,1 & 10 & 140 & 1 & 4 & 8 & 6 \\
\hline pasr-12 & sinter & 5 & 0,1 & 15 & 70 & 0,8 & 23 & 10 & 12 \\
\hline pasr-11 & sinter & 2,5 & 0,8 & 340 & 2200 & 6,4 & 154 & 78 & 700 \\
\hline pasr-9 & sinter & 160 & 0,2 & 17 & 20 & 1,4 & 106 & 8 & 22 \\
\hline pasr-21 & stockwork & 4300 & 38 & 220 & 10000 & 120 & 162 & 760 & 1120 \\
\hline pasr-23 & stockwork & 100 & 4,8 & 30 & 430 & 1 & 52 & 28 & 92 \\
\hline pasr-24 & stockwork & 500 & 1,3 & 50 & 30 & 0,6 & 29 & 8 & 52 \\
\hline pasr-34 & stockwork & 2400 & 28 & 410 & 330 & 7 & 193 & 484 & 1225 \\
\hline pasr-41 & stockwork & 400 & 9,4 & 5200 & 710 & 110 & 49 & 10 & 78 \\
\hline pasr-44 & stockwork & 900 & 2,9 & 50 & 70 & 0,2 & 46 & 16 & 90 \\
\hline pasr-43 & stockwork & 6000 & 4,3 & 110 & 110 & 3 & 54 & 10 & 64 \\
\hline pasr-40 & stockwork & 2550 & 30 & 2600 & 50 & 18 & 58 & 4 & 82 \\
\hline pasr-29 & stockwork & 4600 & 13,5 & 80 & 160 & 3,8 & 429 & 14 & 106 \\
\hline pasr-28 & stockwork & 900 & 3,9 & 200 & 170 & 4 & 56 & 16 & 74 \\
\hline pasr-27 & stockwork & 1900 & 5,6 & 220 & 300 & 5,6 & 66 & 12 & 84 \\
\hline pasr-3 & stockwork & 2500 & 17,5 & 6800 & 100 & 50 & 327 & 28 & 54 \\
\hline pasr-45 & stockwork & 12892 & 29 & 110 & 40 & 3,6 & 76 & 120 & 62 \\
\hline pasr-30 & stockwork & 7600 & 26 & 145 & 240 & 2,8 & 74 & 14 & 56 \\
\hline pasr-38 & stockwork & 1650 & 40 & 110 & 20 & 1,4 & 26 & 20 & 76 \\
\hline
\end{tabular}


Tabla 3

Datos geoquímicos de la Mina Remance (valores de Ag, As, Sb, Cu, Pb y Zn en ppm; Au, y Hg en ppb)

\begin{tabular}{|c|c|c|c|c|c|c|c|c|c|}
\hline Muestra & Descripción & $\mathrm{Au}(\mathrm{ppb})$ & $\mathrm{Ag}$ & As & $\mathrm{Hg}(\mathrm{ppb})$ & $\mathrm{Sb}$ & $\mathrm{Cu}$ & $\mathrm{Pb}$ & $\mathrm{Zn}$ \\
\hline pare-16 & 13303 & 3,6 & 350 & 1900 & 12 & 10 & 34 & 12 & \\
\hline pare-12 & 3400 & 0,7 & 500 & 1000 & 17 & & & & \\
\hline pare-11 & 390 & 0,2 & 350 & 190 & 6,6 & 23 & 14 & 32 & \\
\hline pare-5 & 50 & 0,6 & 25 & 70 & 3 & 75 & 14 & 94 & \\
\hline pare-2 & 1250 & 0,1 & 680 & 3100 & 17 & 36 & 36 & 18 & \\
\hline pare-13 & 220 & 0,1 & 73 & 70 & 3,4 & 0,5 & 36 & 18 & \\
\hline pare-33 & argílica & 2,5 & 0,3 & 60 & 380 & 1,6 & 13 & 14 & 10 \\
\hline pare-7 & argílica & 65 & 0,1 & 130 & 380 & 16,4 & 13 & 6 & 6 \\
\hline pare-6 & argílica & 235 & 1 & 590 & 4700 & 54 & 89 & 40 & 36 \\
\hline pare-26 & argílica & 30 & 0,7 & 32 & 450 & 8 & 81 & 10 & 54 \\
\hline pare-3 & brecha hidrotermal & 520 & 3 & 270 & 450 & 6,4 & 6 & 20 & 24 \\
\hline pare-20 & brecha hidrotermal & 67063 & 234,9 & 3600 & 20000 & 21 & 530 & 300 & 370 \\
\hline pare-17 & brecha hidrotermal & 3850 & 15,3 & 260 & 350 & 5 & 98 & 102 & 136 \\
\hline pare-27 & brecha hidrotermal & 15360 & 16 & 1800 & 19000 & 13 & 152 & 120 & 158 \\
\hline pare-35 & propilítica & 30 & 0,1 & 6 & 20 & 0,4 & 23 & 8 & 78 \\
\hline pare-34 & propilítica & 40 & 0,5 & 10 & 180 & 1 & 1 & 14 & 34 \\
\hline pare-15 & propilítica & 2,5 & 0,1 & 4 & 1000 & 0,3 & 7 & 1 & 90 \\
\hline pare-37 & propilítica & 30 & 0,2 & 6 & 80 & 0,1 & 134 & 4 & 76 \\
\hline pare-29 & propilítica & 40 & 0,3 & 10 & 20 & 1,6 & 26 & 4 & 78 \\
\hline pare-28 & propilítica & 80 & 0,2 & 27 & 500 & 3,2 & 47 & 4 & 66 \\
\hline pare-14 & propilítica & 100 & 2,6 & 190 & 560 & 4,4 & 48 & 14 & 36 \\
\hline pare-4 & stockwork & 901 & 9,9 & 330 & 1700 & 21 & 62 & 26 & 14 \\
\hline pare-40 & roca caja & 5 & 1 & 17 & 20 & 0,1 & 146 & 6 & 80 \\
\hline pare-38 & roca caja & 50 & 0,2 & 5 & 110 & 0,2 & 153 & 6 & 86 \\
\hline pare-39 & roca caja & 2,5 & 6,6 & 7 & 80 & 0,2 & 143 & 6 & 86 \\
\hline pare-24 & roca caja & 2,5 & 0,1 & 5 & 50 & 0,1 & 143 & 10 & 90 \\
\hline pare-36 & roca caja & 5 & 0,1 & 11 & 60 & 6,8 & 21 & 14 & 40 \\
\hline pare-32 & veta & 19474 & 23 & 43 & 10 & 2,4 & 33 & 32 & 16 \\
\hline pare-30 & veta & 5150 & 8 & 60 & 370 & 3,8 & 9 & 28 & 4 \\
\hline pare-31 & veta & 2900 & 5 & 46 & 80 & 3,4 & 13 & 14 & 16 \\
\hline pare-10 & veta & 5500 & 1,9 & 210 & 170 & 6,6 & 50 & 22 & 28 \\
\hline pare-9 & veta & 1005 & 0,7 & 29 & 110 & 1,2 & 0,5 & 14 & 6 \\
\hline pare-23 & veta & 19886 & 7,1 & 46 & 1400 & 2,4 & 2 & 20 & 4 \\
\hline pare-22 & veta & 5350 & 1,6 & 110 & 210 & 5 & 5 & 22 & 20 \\
\hline pare-21 & veta & 320 & 1,1 & 120 & 100 & 2 & 0,5 & 12 & 8 \\
\hline pare- 8 & veta & 8320 & 2,3 & 230 & 1600 & 4,4 & 15 & 22 & 34 \\
\hline pare-1 & veta & 7350 & 7,7 & 210 & 770 & 24 & 10 & 60 & 8 \\
\hline pare-19 & veta & 410 & 2,3 & 70 & 400 & 5,2 & 75 & 12 & 22 \\
\hline pare-25 & veta & 2750 & 19,2 & 70 & 4100 & 2,8 & 195 & 170 & 174 \\
\hline pare-18 & veta & 38263 & 20 & 250 & 690 & 7,8 & 780 & 120 & 110 \\
\hline
\end{tabular}




\section{SAN PEDRITO}

San Pedrito se localiza entre las minas de Remance y Santa Rosa, a unos kilómetros al norte de la Carretera Interamericana (Fig. 2). En este lugar existen varias galerías y trincheras antiguas excavadas por la empresa Panama Corporation durante los años 1920. Freeport perforó durante 1988 cinco pozos con un total de $481 \mathrm{~m}$. Estas perforaciones se realizaron en el prospecto Las Minitas (1 km al noreste de San Pedrito) donde una serie de pequeñas vetillas de cuarzo cortan andesitas propilitizadas.

Dos domos riodacíticos, cada uno con su manto piroclástico alrededor, se encuentran cerca del pueblo de San Pedrito. El domo localizado al oeste y sus rocas piroclásticas asociadas se encuentran argilizados y cortados por vetillas de cuarzo aurífero. En las vetillas de cuarzo se ha observado oro visible y valores de oro anómalos son comunes en los afloramientos. En este lugar nunca se han realizado perforaciones ni trincheras. El domo del este no presenta alteración alguna.

\section{DEPÓSITO REMANCE}

La empresa Veraguas Mining Company produjo 15.500 toneladas con 10,5 gramos de oro por tonelada de la mina Remance durante los años 1800 (Wleklinski, 1969). Adicionalmente la empresa Panama Corporation produjo otras 70.000 toneladas con 12 gramos de oro por tonelada entre los años 1923 y 1932. Minera Remance, los dueños actuales, están en producción desde el año 1989 y cuentan con una reserva reportada de 250.000 toneladas con una ley de corte de 3 gramos por tonelada.

\section{Geología}

El depósito epitermal de oro de Remance esta contenido en un manto de rocas piroclásticas que se vuelve mas grueso conforme se acerca hacia dos cráteres superpuestos. La base del manto piroclástico es una brecha gruesa con fragmentos de andesita fluidal los cuales alcanzan diámetros de hasta un metro. Esta unidad se adelgaza hacia afuera del cráter y está sobreyacida por brechas más finas las cuales contienen fragmentos lapilíticos. La primera unidad del manto piroclástico es una toba cristalina de grano fino o flujo con ocasionales fragmentos líticos. Una fotografía de la base con fragmentos gruesos y de las brechas líticas lapilíticas de la parte superior se presentan en la figura 8 .

Un domo sin mayor alteración se encuentra dentro del cráter y en el flanco sur está cubierto por su propio manto piroclástico. Cinco muestras sin mayor alteración de este complejo varían en composición desde andesita basáltica $\left(56,4 \% \mathrm{SiO}_{2}\right)$ a dacita $\left(67,4 \% \mathrm{SiO}_{2}\right)$. Las cinco muestras solo contienen fenocristales de plagioclasa y piroxeno, lo
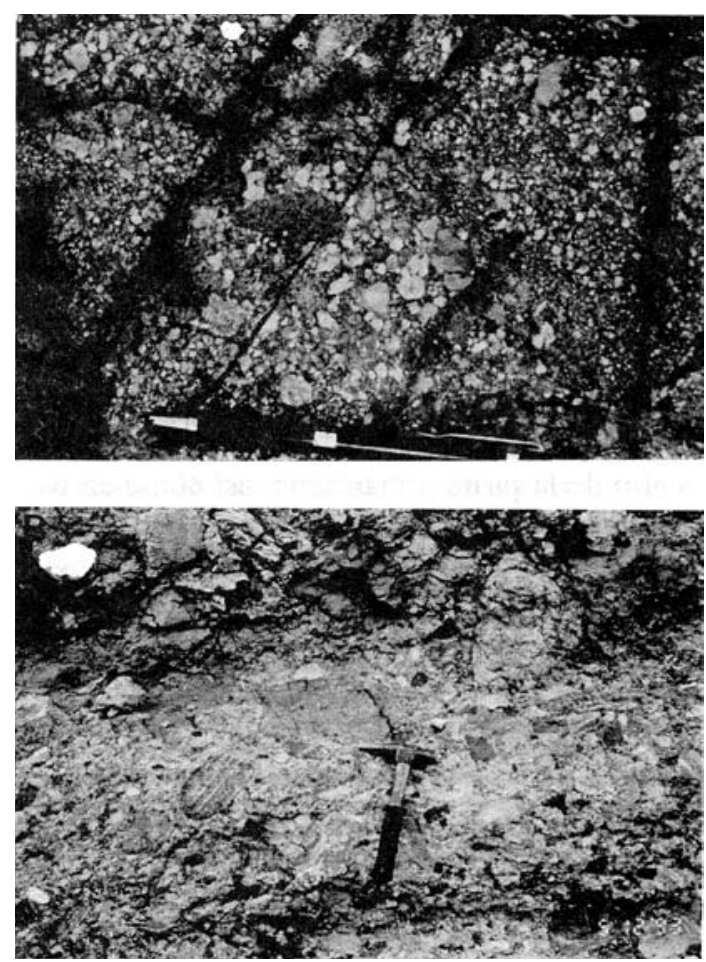

Fig. 8: Brechas tobáceas de la falda piroclástica, Remance. A. Brecha con fragmentos de madera carbonizada dentro de la serie piroclástica. B. Brecha con fragmentos grandes en la base de la serie piroclástica; contiene fragmentos del domo y escasas fragmentos silicificados. 
cual sugiere que mucha de la variabilidad en el contenido de silica es el resultado de la alteración propilítica regional que afecta toda la zona.

\section{Alteración y Mineralización}

La alteración hidrotermal en Remance cubre un área de $10 \mathrm{~km}^{2}$. La alteración argílica y la silicificación, la cual contiene un pequeño porcentaje de pirita diseminada, se encuentran bien desarrolladas, especialmente en el manto piroclástico. La veta principal corta el manto piroclástico y es el principal contenedor de la mineralización. El minado en Remance es por métodos subterráneos. Otras vetas subverticales en Remance son las de Santa Rosa y Consuelo. Estas vetas afloran a lo largo de un kilómetro aproximadamente y la veta principal aflora por alrededor de tres kilómetros.

La silicificación es fuerte a lo largo de la veta principal y en las brechas del conducto hidrotermal adyacentes a la veta. En las operaciones de minado se explota cuarzo bandeado crustiforme de la veta junto con brechas con sulfuros del conducto hidrotermal (Fig. 9A). Brechas de conducto similares se encuentran a lo largo de fallas en Alto de la Mina en el depósito de Santa Rosa (Fig. 9B).

La veta principal tiene en espesor promedio dos metros y contiene cuarzo lechoso y cristalino, ocasionalmente también cuarzo amatista. El oro se presenta como pequeñas inclusiones dentro de la pirita y marcasita, así como en forma de oro libre, diseminado dentro del cuarzo. Como minerales accesorios se encuentran pequeñas cantidades de calcopirita, esfalerita, galena y arsenopirita, siendo los valores de metales base generalmente bajos. En cambio, en el mineral de Remance se encuentran valores elevadas de $\mathrm{Au}$, Ag y As, junto con cantidades anómalas de Sb y localmente Hg. En la tabla 3 se presentan los datos geoquímicos del depósito de Remance.

\section{Potencial para Minado de Gran Volumen}

La veta principal es una estructura mineralizada de discreto potencial para su volumen. Aunque, conforme la estructura se aproxima al cráter
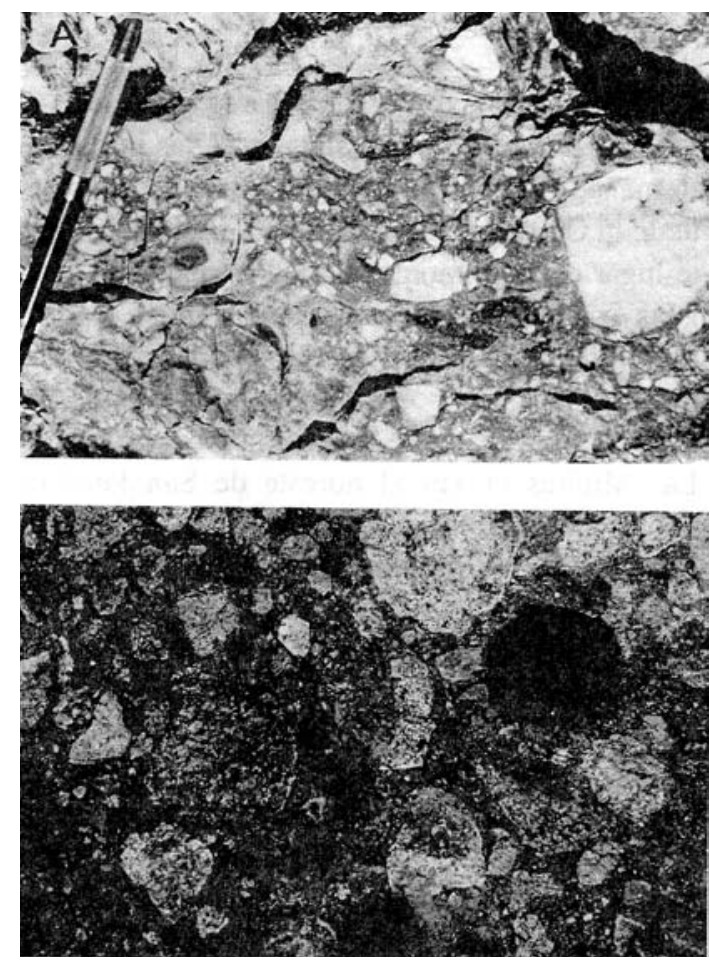

Fig. 9: Brechas hidrotermales de la Franja Aurífera de Veraguas. A. Brecha hidrotermal con matriz y fragmentos silicificados de Remance. B. Brecha hidrotermal heterolítica de Santa Rosa (tajo Alto de la Mina) cementada por una matriz de fragmentos líticos de grano fino.

del Tullido se abre en un stockwork de cuarzo. En el margen del cráter y dentro del graben entre las vetas Principal y Santa Rosa se puede observar como la silicificación se expande en brechas. Aún cuando la mina ha estado en producción durante cuatro años, este stockwork no fue reconocido sino hasta el año 1993 cuando la construcción de un sistema de caminos permitió exponer las rocas mineralizadas. Muestreos de canal y treinta perforaciones de circulación reversa fueron realizados durante el año 1995 con el objetivo de explorar el potencial del manto piroclástico como un depósito de oro de gran tonelaje. La mayoría de las perforaciones contenían intervalos amplios (decenas de metros) con promedios de 200 a 300 ppb de oro con algunos intervalos locales (uno a tres metros de espesor) en el rango de uno a dos ppm de oro. Diez pozos perforados a través de la veta principal 
revelaron la existencia de un stockwork de cuarzo mineralizado alrededor de la veta principal con valores promedios de un ppm de oro.

\section{LOS HATILLOS - AGUACATAL}

Los Hatillos es una veta tipo bonanza de metales base y preciosos contenida en andesitas propilitizadas de la Formación Cañazas (Fig. 1). La veta Blanca es una estructura de uno a dos metros de ancho rodeada por un halo de alteración sericítica. Históricamente el área ha sido objeto de trabajos mineros desde la época precolombina, seguido por trabajos realizados por los españoles alrededor del año 1560 y por último, entre los años 1926 y 1932, la Panama Corporation excavó 300 $\mathrm{m}$ de galerías en dos niveles. Wleklinski (1969) reporta una reserva posible de 30.000 toneladas con 12,5 ppm Au y 21,6 ppm Ag, así como una reserva probable con 11.000 toneladas con $14 \mathrm{ppm} \mathrm{Au}$, $3,1 \% \mathrm{~Pb}$ y $4,3 \% \mathrm{Zn}$ (veta La Blanca).

En el año 1978 el prospecto fue evaluado por la Dirección General de Recursos Minerales, en 1985 por la Duval Corporation, y en 1988 por Freeport.

Aguacatal es un volcán erosionado localizado un kilómetro al este de la veta La Blanca en Los Hatillos. El cráter tiene un diámetro de 1,5 $\mathrm{km}$ y se encuentra rodeado por flujos basálticos inalterados. Estas coladas cubren otros flujos con alteración propilítica y en menor cantidad secuencias de rocas sedimentarias, piroclásticas y epiclásticas. Las quebradas que drenan las paredes del cráter contienen oro visible en concentrados lavados con batea (hasta 300 ppm Au) y en vetillas de cuarzo con rumbo norte se encuentran valores de oro de alta ley. La empresa Minas Santa Rosa perforó nueve pozos en el año 1994.

\section{CONCLUSIONES}

Trabajos de exploración en la Franja Aurífera de Veraguas han dado como resultado el descubrimiento de dos depósitos económicos de oro.
Ambos depósitos se encuentran dentro de domos exógenos y en sus mantos piroclásticos adyacentes. Otros blancos para exploración en la franja se encuentran todavía en la etapa de evaluación temprana. Gran parte de la región todavía tiene que ser mapeada y muestreada con detalle, así como los límites del campo de domos tienen que ser definidos. Aún así, el ambiente geológico ya es foco de atención y esfuerzos para su exploración se encuentran en marcha.

Los campos de domos y sus mantos piroclásticos representan un importante objetivo de exploración en Centroamérica. Los campos de domos son algunas veces difíciles de identificar, especialmente si las rocas han sido afectadas por la alteración hidrotermal; por este motivo pocos aparecen en los mapas geológicos publicados. Aún así, los campos de domos pueden ser encontrados a lo largo de fallas noroeste en las márgenes de grabens desde Panamá hasta Guatemala.

Yacimientos de oro en varios de estos campos de domos se encuentran en producción (p.ej. Santa Rosa) y otros han sido lugar de nuevos descubrimientos de oro (p.ej. Crucitas, Costa Rica).

Los pocos depósitos descubiertos hasta la fecha varían en tamaño entre 0,25 a 2,5 millones de onzas. Aún asi, visto desde la perspectiva del arco circumpacífico, nuevos descubrimientos tienen el potencial para ser mayores en un orden de magnitud. Algunos descubrimientos fueron hechos como producto de la re-evaluación de viejos distritos y ocurrencias ya existentes (p.ej. Santa Rosa, Remance). Otros, como Crucitas, en Costa Rica, se encuentran fuera de areas mineras establecidas sin ninguna actividad de prospección previa.

\section{REFERENCIAS}

JOHNSON, M.D., BIKERMAN, D.\& RUSSELL, M., 1995: Function of contemporary modelling in mine development at Mina Santa Rosa, Veraguas Province, Panama. Soc. Mining Engineers, preprint series. 
JOHNSON, M.D., BIKERMAN, D. \& RUSSELL, M., 1996: Mine development modeling at Mina Santa Rosa in Panama. - Mining Engineering, 48,4: 51-57.

NELSON, C.E. \& GILES, D.L., 1985: Hydrothermal eruption mechanisms and hot spring gold deposits. - Econ. Geol., 80: 1633-1639.

TIPPETT, M.C. \& TREVER, P.F., 1989: The isthmus of Panama - a forgotton El Dorado. - Soc. Mining Engineers preprint number 89-56, 4 págs.
WHITE, D.C., 1993: Geology and mineralization of the Santa Rosa gold deposits, Panama. - Soc.Mining Engineers preprint series, 5 págs.

WLEKLINSKI, S., 1969: Gold deposits of northern Veraguas. - UN Development Program, Mineral Survey of the Azuero Area, 1, 113 págs. 